$11-2017$

\title{
Geo-spatial reporting for monitoring of household immunization coverage through mobile phones: Findings from a feasibility study
}

Abdul Momin Kazi

Aga Khan University, momin.kazi@aku.edu

M. Ali

Aga Khan University, majid.jamali@aku.edu

Ayub Khan

Aga Khan University, ayub.khan@aku.edu

Hussain Kalimuddin

Aga Khan University, hussain.kalimuddin@aku.edu

K. Zubair

Aga Khan University, zubair.karim@aku.edu

See next page for additional authors

Follow this and additional works at: https://ecommons.aku.edu/

pakistan_fhs_mc_women_childhealth_paediatr

Part of the Health Information Technology Commons, and the Pediatrics Commons

\section{Recommended Citation}

Kazi, A., Ali, M., Khan, A., Kalimuddin, H., Zubair, K., Kazi, A., Artani, A., Ali, S. (2017). Geo-spatial reporting for monitoring of household immunization coverage through mobile phones: Findings from a feasibility study. International Journal of Medical Informatics, 107, 48-55.

Available at: https://ecommons.aku.edu/pakistan_fhs_mc_women_childhealth_paediatr/323 


\section{Authors}

Abdul Momin Kazi, M. Ali, Ayub Khan, Hussain Kalimuddin, K. Zubair, A.N. Kazi, Azmina Artani, and Syed Asad Ali 


\section{Accepted Manuscript}

Title: Geo-Spatial Reporting for monitoring of household immunization coverage through Mobile Phones; Findings from a Feasibility Study

Authors: A.M. Kazi, M. Ali, K. Ayub, H. Kalimuddin, K.

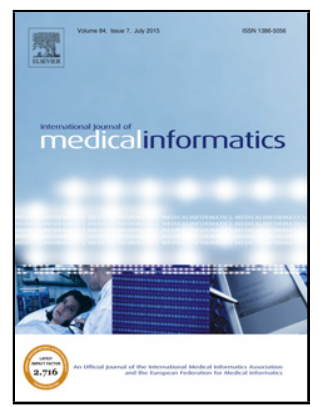
Zubair, A.N. Kazi, A. Artani, S.A. Ali

PII: S1386-5056(17)30227-7

DOI:

Reference: http://dx.doi.org/10.1016/j.ijmedinf.2017.09.004

To appear in: IJB 3554

Received date: International Journal of Medical Informatics

Revised date:

4-12-2016

Accepted date:

Please cite this article as: A.M.Kazi, M.Ali, K.Ayub, H.Kalimuddin, K.Zubair, A.N.Kazi, A.Artani, S.A.Ali, Geo-Spatial Reporting for monitoring of household immunization coverage through Mobile Phones; Findings from a Feasibility Study, International Journal of Medical Informaticshttp://dx.doi.org/10.1016/j.ijmedinf.2017.09.004

This is a PDF file of an unedited manuscript that has been accepted for publication. As a service to our customers we are providing this early version of the manuscript. The manuscript will undergo copyediting, typesetting, and review of the resulting proof before it is published in its final form. Please note that during the production process errors may be discovered which could affect the content, and all legal disclaimers that apply to the journal pertain. 


\title{
Geo-Spatial Reporting for monitoring of household immunization coverage through Mobile Phones; Findings from a Feasibility Study
}

\author{
Authors: Kazi AM${ }^{1}$, Ali $\mathbf{M}^{1}$, K Ayub ${ }^{1}$, Kalimuddin $\mathbf{H}^{1}$, Zubair $\mathrm{K}^{1}$, Kazi AN $^{1}$, Artani A $^{2}$, Ali SA ${ }^{1}$
}

Affiliations:

[1] Department of Paediatrics and Child Health, Aga Khan University, Karachi, Pakistan ${ }^{1}$

[2] Department of Medicine, Aga Khan University, Karachi, Pakistan ${ }^{2}$

\section{Corresponding Author:}

Abdul Momin Kazi

Momin.kazi@aku.edu

Department of Paediatrics and Child Health, Aga Khan University, Stadium Road, PO Box 3500,

Karachi 74800, Pakistan

Phone: +92 2134864955 . Fax+92 2134934294

\section{HIGHLIGHTS}

- With highly accessible and low-cost coverage of mobile phones in Pakistan, GPS enabled smart phones can be used for facilitating data collection, research and health management.

- We piloted the use of this GPS system to improve the efficiency of field-based health providers and health managers for monitoring of the immunization program.

- The GIS data and e-Maps generated through this system were linked with coverage data obtained from mobile phone based system for monitoring polio SIAs campaigns

- We were able to show the strength and innovation of GPS system targeted for vaccination surveys and Supplementary Immunization Activity (SIA) in resource constrained and security compromised areas.

\begin{abstract}
Background

The addition of Global Positioning System (GPS) to a mobile phone makes it a very powerful tool for surveillance and monitoring coverage of health programs. This technology enables transfer of data directly into computer applications and cross-references to Geographic Information Systems (GIS) maps, which enhances assessment of coverage and trends.
\end{abstract}

\section{Objective}

Utilization of these systems in low and middle income countries is currently limited, particularly for immunization coverage assessments and polio vaccination campaigns. We piloted the use of this system and discussed its potential to improve the efficiency of field-based health providers and health managers for monitoring of the immunization program.

\section{Methods}

Using " $30 \mathrm{X} 7$ " WHO sampling technique, a survey of children less than five years of age was conducted in random clusters of Karachi, Pakistan in three high risk towns where a polio case was detected in 2011. Center point of the cluster was calculated by the application on the mobile. Data and location coordinates were collected through a mobile phone. This data was linked with an automated mHealth based monitoring system for monitoring of Supplementary Immunization Activities (SIAs) in Karachi. After each SIA, a visual report was generated according to the coordinates collected from the survey.

\section{Result}


A total of 3535 participants consented to answer to a baseline survey. We found that the mobile phones incorporated with GIS maps can improve efficiency of health providers through real-time reporting and replacing paper based questionnaire for collection of data at household level. Visual maps generated from the data and geospatial analysis can also give a better assessment of the immunization coverage and polio vaccination campaigns.

\section{Conclusion}

The study supports a model system in resource constrained settings that allows routine capture of individual level data through GPS enabled mobile phone providing actionable information and geospatial maps to local public health managers, policy makers and study staff monitoring immunization coverage.

\section{Keywords: Global Positioning System; Geographic Information System; Vaccination Coverage; Polio; Supplementary Immunization Activity; Monitoring; Geo-Spatial Reporting; Mobile Phones}

\section{BACKGROUND:}

The exponential boom in the telecommunication industry across the globe has enabled better and advanced initiatives linking the concept of healthcare with the use of mobile phone applications. Mobile phone technology has aided in making data collection processes easier and accurate [1]. It has also enabled direct digital data entry into mobile phone application at the point of data collection allowing the ability to enter, review and analyze data in real-time [2]. Recent studies have indicated the effective use of mobile phones as a means of locating target populations, assessing issues pertinent to health care facilities and expanding health literacy among local communities, especially in low income countries [3]. Further the introduction of Global Positioning System (GPS) during data collection in mobile phones and cross-referencing it to Geographic Information Systems (GIS) maps has been a valuable development. This cost-effective measure in public health care settings has enabled obtaining clear presentation of data of the participant's environment. This in turn, promises a better assessment approach of trends and correlations to allow improvement in the planning, monitoring and surveillance of public health programs in developing countries [4-6].

Childhood immunization is a cornerstone in reducing morbidity and mortality among children under five. Globally, various programs have been initiated to immunize each child against vaccinepreventable diseases along with setting up targets and evaluating goals periodically. Countries with endemic vaccine-preventable illnesses such as India, Nigeria and Mozambique have employed GIS technology to monitor and improve coverage rates setting up examples for other developing countries. Despite these technologies being increasingly used to evaluate the distribution of health services, inability to operate GPS devices indoor, complexity of stand-alone GIS software, and infrastructure required for linking GIS maps with the paper or electronic data and collecting of coordinates due to safety conducts or local bye in are still some of the hindrances for use of these tools in resource constrained settings [7-9].

Unfortunately, routine immunization coverage in Pakistan is still below the desired level due to multiple challenges faced by the country's Expanded Program of Immunization (EPI), leading to thousands of deaths from vaccine-preventable childhood illnesses [10].Pakistan is among the three remaining endemic countries besides Afghanistan and Nigeria reporting Polio positive cases and struggling with interruption of poliovirus transmission [11]. Also, the country experiences multiple measles outbreaks, resulting in large numbers of morbidity and mortality among affected children [12].A number of factors influence low immunization coverage in Pakistan among which inaccurate vaccine coverage estimates and lack in accountability at the district level are major concerns. 
The government of Pakistan in collaboration with international agencies is working on introducing different strategies to improve the immunization coverage as well as strengthening monitoring approach in the field during Supplementary Immunization Activities (SIA)[10, 13].Stringent monitoring of immunization activities at the field and household level plays an essential role in boasting immunization coverage. However, in Pakistan, immunization activities are greatly affected by poor access to remote communities, accountability of the vaccinators, variable sociopolitical circumstances and poor governance at the district levels[14].

In order to ensure accountability and overcome these challenges, better monitoring tools and strategies are needed to determine coverage during each immunization campaign and Polio supplementary immunization campaigns. Pakistan is a developing country, currently possessing a strong network of mobile connectivity with around 140.5 million subscribers covering all socioeconomic strata [15]. Since 2014, an escalating trend has also been observed in the acceptance of smart phones as compared to feature phones in Pakistan. With increase uptake of mobile phone technology, mobile health or mHealth based interventions can be planned and implemented to improve immunization coverage and access to primitive groups in the community via short messaging service (SMS) and voice call based interventions [16].

In this study, we lay out a foundation for using geospatial map to monitor and visualize immunization coverage at the household and town level using mobile phone to collect location coordinates and baseline survey close to real time. Further we compared these maps obtained through a mHealth based and conventional lot quality assurance system (LQAS) monitoring system to evaluate polio supplementary immunization coverage at a household level. In this paper, we have described the process and discussed the potential of this strategy to improve the efficiency of field-based health providers and health managers for implementation and monitoring of the program.

\section{METHODS}

\section{Study Site:}

This study was conducted in Karachi. It is among the world's largest cosmopolitan cities with an estimate 21 million people $[\mathbf{1 7}, \mathbf{1 8}$. Being the financial and commercial hub of Pakistan, there is an annual $5 \%$ population rise in Karachi [19]

\section{Sampling Methodology:}

Using "30 X 7" WHO sampling technique for cluster identification, a baseline survey for an mHealth based monitoring system to evaluate the polio supplementary immunization activity was conducted [17].Karachi city consist of 18 towns with approximately 7750 clusters, with each cluster compromising of around 250 households[20]. The study data was collected on GPS enabled smart phones. Thirty clusters each were randomly selected from three towns of Karachi (i) Gulshan e Iqbal, (ii) Baldia and (iii) SITE having at least one confirmed case of Polio in 2011 culminating to 120 clusters[21]. Each cluster consisted of around 200 to 250 households.

The baseline data was collected from January to March 2012 and visual reports of 7 SIAs conducted in 2012 and 2013 were generated, Figure1 depicts the study area.

\section{GIS Mapping Process \\ Mapping of Towns}

Town boundaries were digitized by acquiring municipality maps and taking GPS co-ordinates of various locations including points on boundary and landmarks. To achieve this task; as a first step, Google Earth ${ }^{\circledR}$ was used to identify famous points in the locality and field visits were made to acquire co-ordinates using GARMIN eTrex Venture HC device. Municipality maps were scanned and geocoded in Esri ArcGIS version 9.3.1, boundary and major landmarks were digitized.

\section{Mapping of Study Clusters}


At the community level after the boundary of the cluster was physically identified, the mapping team marked the entire boundary using GPS device track mode. Cluster boundaries of randomly selected clusters were digitized using GPS device track mode. Points on town boundaries and landmarks were used as geo-referencing points. GPX files from device were transferred to Google Earth for finetuning and then imported to ARCGIS using KML to SHP interoperability functions. Important landmarks within the cluster were also digitized and center points of the entire clusters were calculated.

Arcpad ${ }^{\circledR}$ application had two modules; 1) locating the cluster center point and 2) data acquisition. All digitized maps and center points were incorporated in smartphone with ESRI Arcpad 8. This allowed live maps of each cluster or block to appear with a specific center point. This synchronization allowed the field data collectors to coordinate their travel through the given block or cluster designated to them for data collection (Figure 2).

\section{Data collection tool}

Hardware: Data collection and cluster center point location was done through smart phones with windows mobile 6.5 (Microsoft Corporation, Redmond, WA) operating system. Major features of the smart phone included, a-GPS capability, long battery life and TouchFLO finger swipe navigation. SD card slot was also available and used for data storage. All smart phones were housed in the hard file covers to protect it from theft, accidental drop and to carry additional batteries and car charges. GARMIN eTrex Venture ${ }^{\circledR}$ HC GPS device was used for digitizing cluster boundaries.

Software: ESRI software were used for both data collection and mapping. ARCMAP 9.3.1 ${ }^{\circledR}$ was used as a desktop application and ACRPAD $8{ }^{\circledR}$ was used on smart phones. Data collection forms were designed and customization for skips and logical/inconsistency checks was done using ARCPAD Studio and VBA (visual basic script).

\section{Training Session and Pilot testing at the field site:}

A five days training session was conducted for study staff with interactive sessions and presentations related to study protocol and working of smartphones and use of GIS maps. This was followed by pilot testing at the community level and additional training on phone maintenance, battery charging, data backup and handling of smart phones at the household level.

\section{Data Security}

Phones and GIS/data server were password protected. To avoid data loss, phones were synced daily with the server and an offsite backup was taken on weekly basis. Codes were assigned to individual devices, which were accessible to study staff only. Passwords were assigned to the machines storing the data and only accessible to authorized personnel. Mobile phones were stored in locked cabinets. Electrical backups for the server were placed to ensure continuous availability.

\section{mHealth based intervention:}

After selection of a cluster, the selection of household data collectors was done by going to the center of cluster, via GIS mapping, determining direction by rotating bottle and proceeding in the bottle's direction. A random household in the indicated directions was chosen, and then every 3rd household was visited (systematically) from the random start, and checked for inclusion criteria. Parents were informed about the study, and asked if they would consent to participate in the Kazi et al study [22]. If the child was not available, had moved or if the parents refused consent, then the 3rd household was approached until an eligible child was found and enrolled. Only one child from one household was recruited. If a household has more than one eligible child than child was selected by randomly selected smart phone generated program.

After parental consent, the selected child's name and age, along with the cell phone number of either parent (or guardian) was recorded. Preferred language of the parents for the SMS messages was recorded. Unique- structured labels were also given to all households from which a child was enrolled, and were noted on a GIS map. 
The information obtained through this baseline survey, including mobile phone numbers and language preferences, was incorporated in an mHealth based monitoring system. A computerized application was developed and two SMS messages were sent after each SIA inquiring through this system (i) "did the vaccinator visited their house in the last Polio SIA campaign" and (ii) "did the enrolled child receive oral polio vaccine". In case there was no response to the SMS message, a call was made on participant's mobile phone to get an answer. Coverage data obtained after each SIA through SMS and phone calls was linked to the GIS database and visual report identifying the coverage data were shared with ground team, study partners and policy makers. This mHealth based monitoring system laid a foundation for monitoring of future SIAs by identifying polio vaccination coverage according to clusters and town.

\section{Ethics:}

Ethical approval of the study was given by Aga Khan University Ethical Review Board and World Health Organization Ethical Review Board.

\section{RESULTS}

\section{Facilitation in Baseline Data Collection Process:}

After selecting the cluster, the data collectors navigated to the center of a cluster using electronic map on mobile phone. Center of the cluster was calculated using GIS algorithm and these maps were incorporated in the mobile phone device. Since the structures of the study area were not pre mapped, GPS helped the field team to reach the center point of each cluster included at the baseline.On reaching center point of a cluster at the field site, households within the cluster were identified using bottle technique which allowed selection of every $3^{\text {rd }}$ house from the center of the identified cluster.

Visual maps generated from the data collected gave a comprehensive projection of the baseline survey data according to the geographical location in close to real time. Visual maps of the data collected were assessed daily in order to evaluate whether data was collected according to the study protocol from within the designated clusters. If a household was selected from outside the clusters boundary, the study staff was asked to re-interview a new household within the designated cluster on the next working day. Geospatial analyses of the data helped in visualizing the data and correlate different variables of the baseline survey according to the geographical location(Figure 3).

\section{Baseline Survey Data:}

A total of 3535 households were included, with 1892 (54\%) male children and 1643 (46\%) female children consented for participation (Table 1).

\section{Coverage Data of Clusters:}

The vaccination coverage data from the three high risk towns of Karachi, obtained after each of the seven SIAs was obtained. The LQAS monitoring data for the SIAs in same regions (where available) which is the conventional method of monitoring SIAs is listed and compared to the estimates obtained in our study (Table 2).

\section{Geospatial Data:}

Georeferencing of the replies on the question whether the child received the polio vaccinator not was conducted according to the household's location in the seven SIAs included in the mHealth based monitoring study. Immunization coverage data was plotted both according to the exact location of the household and coverage density within the town boundary. In addition, density maps according to LQAS data (where available) within town boundaries were also plotted for comparability (Figure 4).

\section{DISCUSSION}

In our study, we were able to show the strength and innovation of our system targeted for vaccination surveys and SIAs in resource constrained and security compromised areas. Unlike other studies, we 
designated independent personnel for data collection team to record coordinates for town and cluster boundaries which minimized the chance of artifacts and acquisition of false co-ordinates. Also, we integrated coordinates into Google Earth ${ }^{\circledR}$ that enhanced visibility of local landmarks making identification of places easier for the data collectors than traditional hand drawn markings. This feasibility study is first of its kind to discuss geospatial mapping for monitoring of household polio vaccination coverage in Pakistan.

With high accessibility of mobile phones in Pakistan, GPS enabled mobile phones can be used for facilitating data collection, research and health management [23]. GPS based data collection and plotting geospatial data has been successfully conducted related to Polio immunization campaigns in

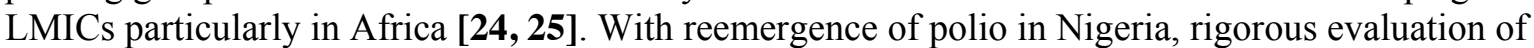
the immunization coverage at the household level is highly needed to eliminate and sustain polio eradication [25]. Similar systems with real time reporting incorporated with GIS maps and spatial reports can improve the immunization coverage including polio vaccination coverage in Pakistan. Moreover, field data collectors were specifically instructed to open the mobile phone based questionnaire in open space in order to capture the GPS coordinates through satellite, eliminating the possibility of low indoor signals [26].

In conjunction with the visual reports obtained after different SIAs, geospatial analysis can help predict good and bad coverage areas. After evaluating the spatial data and feedback from the data collection teams, we were able to identify areas with minimum coverage. With exception of other minor causes, we determined that security issues have a pivotal role in the vaccination coverage and risks involved to the teams. Making use of the GPS technology, safety of the data collection teams could be ensured and appropriate measures can be taken involving stakeholders of these communities for optimizing immunization coverage in such settings. Despite these issues, no harm was reported to the data collection team or to the gadgets during our study making this mode of data collection quite practical in Pakistani settings.

Since GPS coordinates of each household was recorded and each child was given unique identifier during the study, it became quite convenient to revisit any household for follow-ups, quality checking, monitoring or any other purpose. We feel this is a major advantage in tracing a household rather using postal address or relying of study staff in slums, peri-urban and rural localities[27].In Nigeria, GIS maps of the vaccinator catchment area for polio vaccination coverage were developed and mobile phones with GPS devices were used to track the movement and identify the area covered by the vaccinator[28]. However, in our study, once a new questionnaire was selected the coordinates of the location were automatically extracted. This helped in correlating the variables in the questionnaires with the geographical locations, and conducting geospatial analysis to generate reports and maps identifying vaccination coverage and other relevant data. Data from the GPS tracking mode can identify whether vaccinator reached the household or not, but it cannot assess polio vaccination coverage rate, as a response needs to be linked with household location identifying whether the child received the vaccine or not.

The coordinates of the same population can be assessed longitudinally for different intervention and programmatic evaluations. The GIS data and e-Maps generated through this system were linked with coverage data obtained from mobile phone based system for monitoring polio SIAs campaigns[22].The visual reports and GIS maps of the coverage data of SIAs generated through this system were shared with ground teams and local and international policy makers to facilitate them in monitoring and evaluating the SIAs in Karachi[29]. Since the town boundaries and basic landmarks were mapped, monitoring obtained without coordinates or exact household location can also be linked to LQAS data showing density maps of vaccination coverage. This method could be equally applicable in evaluating programs for example the directly observed treatment approach for tuberculosis and malaria eradication program.

Attribution of this smooth transition to GPS based data collection tools could be due to the current advancements, increase accessibility to technology and excessive mobile phone exposure among the 
masses from all socioeconomic backgrounds [30]. Once the data is transferred from mobile phone to the server, it can be collated and analyzed with geographical location on a central database in real time and can be immediately shared with multiple policy makers and partners. Generation of such maps in real time can help minimize any possibility of anomalies of data collected at the house hold level along with an immediate visualization of the information collected with location [30]. Similarly, simultaneous transfer of collected data from mobile phones to the computer sever, allows bypass of the human error factor of data entry. Using the real time advantage of data entry and GIS mapping, both factors can be examined to ensure data completeness [31].GPS technology can also validate access to the vaccinator. Though SMS and voice call based approaches do give some idea about immunization coverage, it relies highly on the responders to generate this data. In contrast, GPS coordinates generated during immunization surveys from each household can proved close estimation of the coverage rate and will enable identify pockets of unvaccinated children that may become a focus in the subsequent SIAs.

There were few limitations currently with the technique and our study. One of the major problems encountered in the field site was the low battery life of the mobile phone with GPS application. To counter, data collectors were given an extra fully charged external source of battery for use and one person was specifically assigned to charge all phone batteries each day. Additionally, the field workers require extensive training and refreshers on mobile phones use and support for issues with GPS applications. Finding this expertise in low resource setting is difficult, and could be one of the reasons why mobile phone technology with GPS application is not been fully implemented globally[26]. Data was transferred through USB cable from the mobile phone rather than internet or GSM edge technology from the field site due to connectivity issues, with availability of $3 \mathrm{G}$ and $4 \mathrm{G}$ technologies data can be transferred in real time from the household level. It has an expensive costing as compared to the model without use of technology, however with the widespread use cheaper phone sets and data services will be available, the costs are expected to reduce over time, thus making the technology more cost effective [32]. Although mobile phones used in this study cost US \$200, with influx of different mobile phone manufactures in the market, cheaper models with similar capabilities are available. For geospatial reports, we used ARCGIS ${ }^{\circledR}$ and further incorporated the maps from freeware Google Earth ${ }^{\circledR}$ version. However, this system can be designed on any GPS enabled mobile phone with any operating system and platform and freeware GIS software's having similar capabilities are available.

\section{CONCLUSION}

This study supports a model system that allows routine capture of individual level data through GPS enabled mobile phone providing actionable information and maps to local public health managers, policy makers and study staff monitoring vaccination coverage. We have described easy to implement real time system for spatial reports related to immunization survey and SIA campaigns in resource constrained and vulnerable settings. This mapping system can be employed for polio vaccination surveys and SIA monitoring in many developing countries. The combination of geospatial mapping both through free and licensed software maps makes it a highly reliable and accessible system. Future studies may look into its acceptability rates within the communities and the data collectors to reach to vulnerable populations and may discuss coverage indicators which were beyond the scope of the current study.

\section{Summary Points:}

- The addition of Global Positioning System (GPS) to a mobile phone makes it a very powerful tool for surveillance and monitoring coverage of health programs.

- This technology enables transfer of data directly into computer applications and cross-references to Global Information Systems (GIS) maps, which enhances assessment of coverage and trends.

- The study supports a model system in resource constrained and vulnerable settings that allows routine capture of individual level data through GPS enabled mobile phone 
- The study provided actionable information and maps to local public health managers, policy makers and study staff monitoring immunization coverage.

\title{
AUTHOR CONTRIBUTIONS
}

- Conceived the topic and designed the experiments: Abdul Momin Kazi, Syed Asad Ali, Murtaza Ali

- Executed the experiments: Abdul Momin Kazi, Murtaza Ali, Ayub Khan, Hussain Kalimuddin, Khurram Zubair

- Wrote the paper: Abdul Momin Kazi, Abdul Nafey Kazi, Artani Ali, Syed Asad Ali

\section{Acknowledgements:}

This study was funded by the World Health Organization (grant 2011/178719-0).

\section{Conflict of interests:}

None declared.

\author{
Abbreviations: \\ GPS: Global Positioning System \\ GIS: Geographic Information System \\ SIA: Supplementary Immunization Activity \\ EPI: Expanded Program on Immunization \\ ERB: Ethical Review Board \\ GSM: Global System for Mobile \\ USB: Universal Serial Bus \\ WHO: World Health Organization
}

\section{REFERENCES}

1. Koop A, Mosges R. The use of handheld computers in clinical trials. Control Clin Trials 2002 Oct;23(5):469-80. PMID:12392861

2. Walther B, Hossin S, Townend J, Abernethy N, Parker D, Jeffries D. Comparison of Electronic Data Capture (EDC) with the Standard Data Capture Method for Clinical Trial Data. PLoS One;2011; 6(9): e25348. doi: 10.1371/journal.pone.0025348. Epub 2011 Sep 23.

3. DeRenzi B, Borriello G, Jackson J, Kumar V, Parikh T, Virk P et al. Mobile Phone Tools for Field-Based Health care Workers in Low-Income Countries. Mount Sinai Journal of Medicine: A Journal of Translational and Personalized Medicine. 2011;78(3):406-418.

4. Cromley EK. GIS and disease. Annu Rev Public Health; 2003; 24:7-24. PMID:12668753

5. Yu P, de Courten M, Pan E, Galea G, Pryor J. The development and evaluation of a PDA-based method for public health surveillance data collection in developing countries. Int J Med Inform; 2009 Aug; 78(8):532-42. doi: 10.1016/j.ijmedinf.2009.03.002. Epub 2009 Apr 15.

6. Booman M, Durrheim DN, La Grange K, Martin C, Mabuza AM, Zitha A, Mbokazi FM, Fraser C, Sharp BL: Using a geographical information system to plan a malaria control programme in South Africa. Bull World Health Organ; 2000; 78:1438-1444. PMID:11196490

7. Gammino VM, Nuhu A, Chenoweth P, Manneh F, Young RR, Sugerman DE, et al. Using geographic information systems to track polio vaccination team performance: pilot project report. Journal of Infectious Diseases. 2014;210(suppl 1):S98-S101

8. Thomson M, Connor S, O'Neill K, Meert JP: Environmental Information for Prediction of Epidemics. Parasitology Today; 2000 April; 16(4):137-138. PMID:10725896

9. Sipe N, Dale P: Challenges in using geographic information systems (GIS) to understand and control malaria in Indonesia. Malaria Journal; 2003 Nov; 2(1):36. PMID: 14613511 
10. Owais A, Khowaja AR, Ali SA, Zaidi AK. Pakistan's expanded programme on immunization: An overview in the context of polio eradication and strategies for improving coverage. Vaccine2013 July; 31(33):3313-9. doi: 10.1016/j.vaccine.2013.05.015. Epub 2013 May 22.

11. Progress towards eradicating poliomyelitis: Afghanistan and Pakistan, January 2011-August 2012. WklyEpidemiol Rec2012 Oct;87(40):381-8.PMID:23074736

12. Khan T, Qazi J. Measles outbreaks in Pakistan: causes of the tragedy and future implications. Epidemiology Reports. 2014;2(1):1

13. World Health Organization. http://www.emro.who.int/pak/who-presence-in-pakistan/. Archived at: http://www.webcitation.org/6KaSMv8yq

14. Khan T, Qazi J. Hurdles to the global antipolio campaign in Pakistan: an outline of the current status and future prospects to achieve a polio free world. Journal of Epidemiology and Community Health. 2013;67(8):696-702.

15. INP M. Mobile phone users cross 140.5 million [Internet]. The Nation. 2017 [cited 11 August 2017]. Available from: http://nation.com.pk/business/01-Aug-2017/mobile-phone-users-cross1405-million

16. Studying Pakistan's growing obsession with smartphones - The Express Tribune [Internet]. The Express Tribune. 2017 [cited 11 August 2017]. Available from: https://tribune.com.pk/story/1060520/studying-pakistans-growing-obsession-with-smartphones/

17. The largest cities in the world and their mayors. Available from http://www.citymayors.com /statistics/largest-cities-mayors-comments.html. Archived at: http://www.webcitation.org/6KaTA9o3J

18. Sindh Population surges by $81.5 \%$, households by $83.9 \%$. The News 2012 April 12 . Available from http://www.thenews.com.pk/Todays-News-13-13637-Sindh-population-surges-by-81.5-pc,households-by-83.9-pc. Archived at: http://www.webcitation.org/6KaT1uQbo

19. Karachi population explosion far greater than experts. Pakistan Today 2011 December 6. http://www.pakistantoday.com.pk/2011/12/06/city/karachi/karachi\%E2\%80\%99s-populationexplosion-far-greater-than-experts $\% \mathrm{E} 2 \% 80 \% 99$-calculations/. Archived at: http://www.webcitation.org/6KaSwUmY0

20. Woodward SH. Description and comparison of the methods of cluster sampling and lot quality assurance sampling to assess immunization coverage Geneva: World Health Organization; 2001

21. Weekly AFP surveillance update, Pakistan, week 52 Islamabad: World Health Organization; 2011.

22. Kazi A, Murtaza A, Khoja S, Zaidi A, Ali S. Monitoring polio supplementary immunization activities using an automated short text messaging system in Karachi, Pakistan. Bulletin of the World Health Organization. 2013;92(3):220-225.

23. Fisher RP, Myers BA. Free and simple GIS as appropriate for health mapping in a low resource setting: a case study in eastern Indonesia. International Journal of Health Geographics; $2011 \mathrm{Feb}$; 10:15. doi: 10.1186/1476-072X-10-15.

24. Barau I, Zubairu M, Mwanza MN, Seaman VY. Improving polio vaccination coverage in Nigeria through the use of geographic information system technology. Journal of Infectious Diseases. 2014;210(suppl 1):S102-S10

25. Abimbola S, Malik AU, Mansoor GF. The final push for polio eradication: addressing the challenge of violence in Afghanistan, Pakistan, and Nigeria. PLoS Med. 2013;10(10):e1001529

26. Gammino VM, Nuhu A, Chenoweth P, Manneh F, Young RR, Sugerman DE, et al. Using geographic information systems to track polio vaccination team performance: pilot project report. Journal of Infectious Diseases. 2014;210(suppl 1):S98-S101

27. Dwolatzky B, Trengove E, Struthers H, McIntyre JA, Martinson NA. Linking the global positioning system (GPS) to a personal digital assistant (PDA) to support tuberculosis control in South Africa: a pilot study. International Journal of Health Geographics; 2006 Aug, 5:34. PMID: 16911806

28. GIS Mapping \& GPS Tracking for Polio in Nigeria. $\mathrm{http}: / /$ mobile.thegatesnotes.com/Topics/Health/GIS-Mapping-GPS-Tracking-for-Polio-in-Nigeria

29. Kazia AM, Jafria LA. The use of mobile phones in polio eradication. Bull World Health Organ 2016;94:153-154 
30. VandenEng JL, Wolkon A, Frolov AS, Terlouw DJ, Eliades MJ, Morgah K, Takpa V, Dare A, Sodahlon YK, Doumanou Y, Hawley WA, Hightower AW. Use of handheld computers with global positioning systems for probability sampling and data entry in household surveys. Am J Trop Med Hyg; 2007 Aug;77(2):393-9. PMID:17690421

31. Shirima K, Mukasa O, Schellenberg JA, Manzi F, John D, Mushi A, Mrisho M, Tanner M, Mshinda H, Schellenberg D. The use of personal digital assistants for data entry at the point of collection in a large household survey in Southern Tanzania. Emerg Themes Epidemiol; 2007 June; 4:5. PMID:17543099

32. Thomson M, Connor S, O'Neill K, Meert JP: Environmental Information for Prediction of Epidemics. Parasitology Today; 2000 April; 16(4):137-138. PMID:10725896

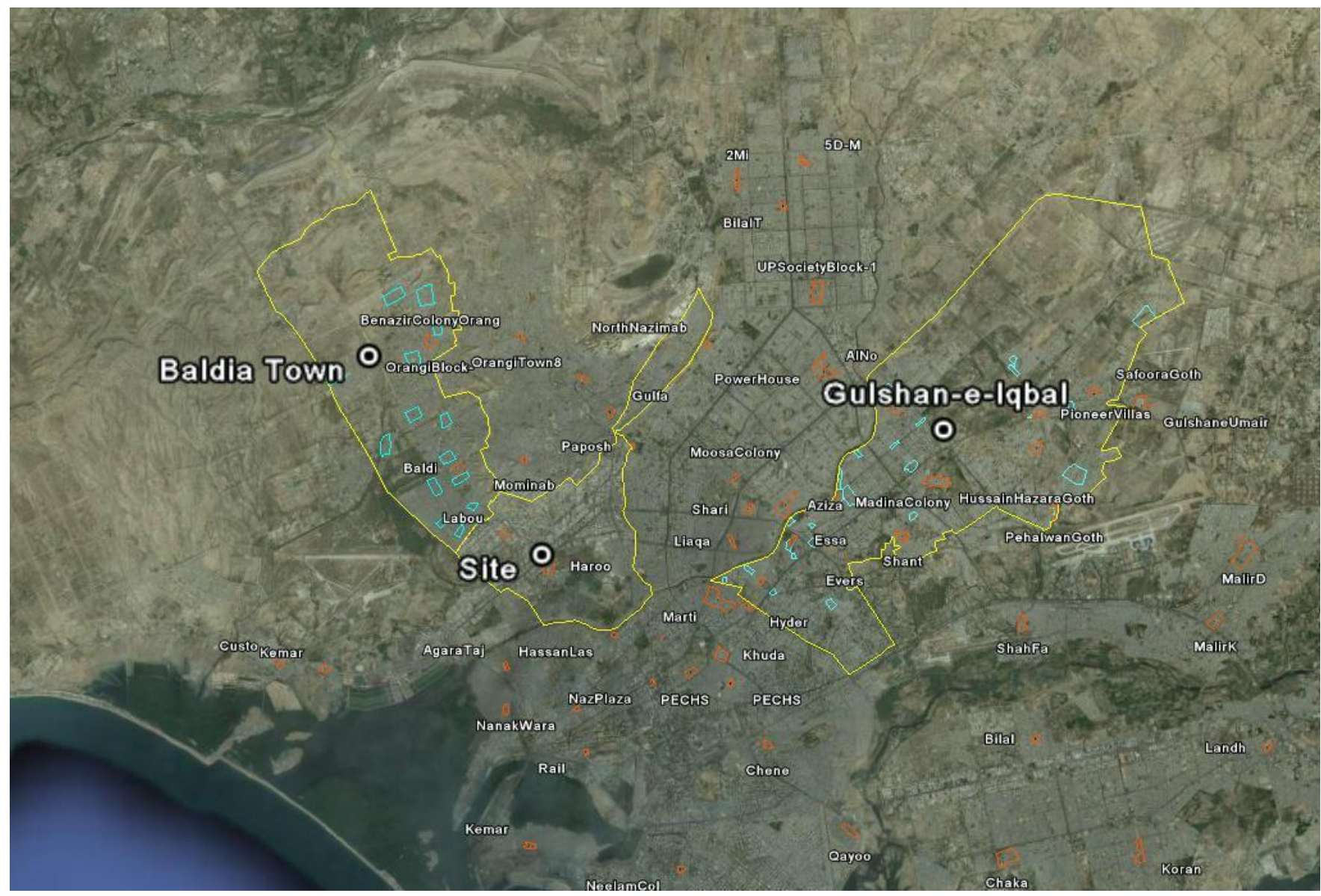

Figure 1: Google Earth Maps identifying all clusters with names in the entire Karachi and three high risk towns-Baldia, Gulshan-e-Iqbal- Site 


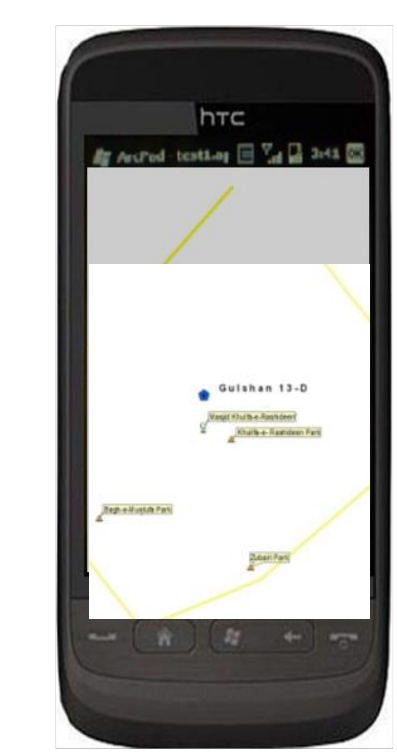

Getting directions for center on of the cluster

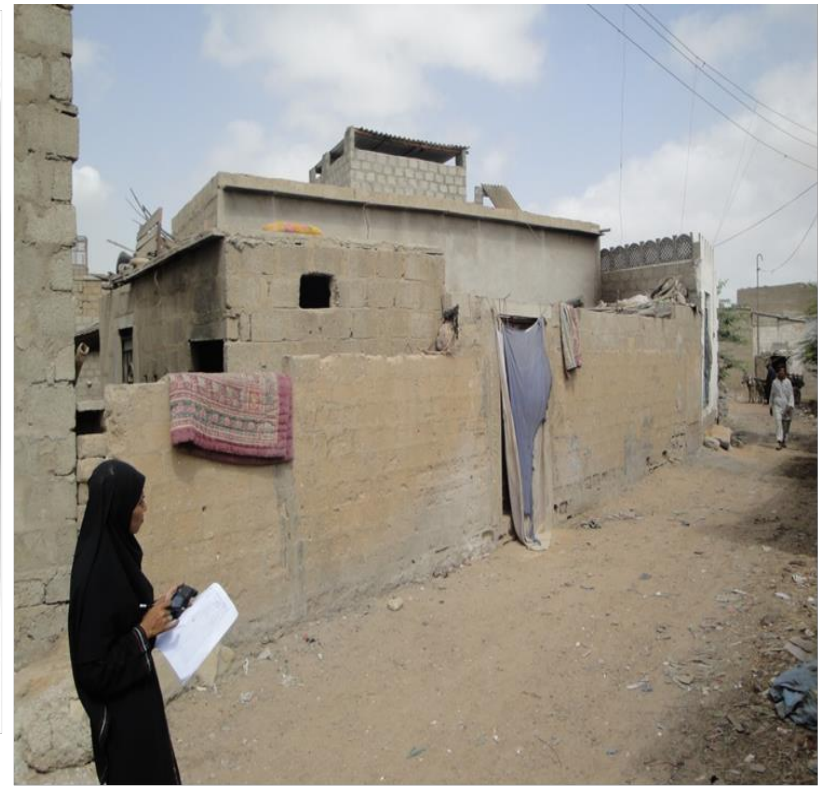

Worker in the field locating a household

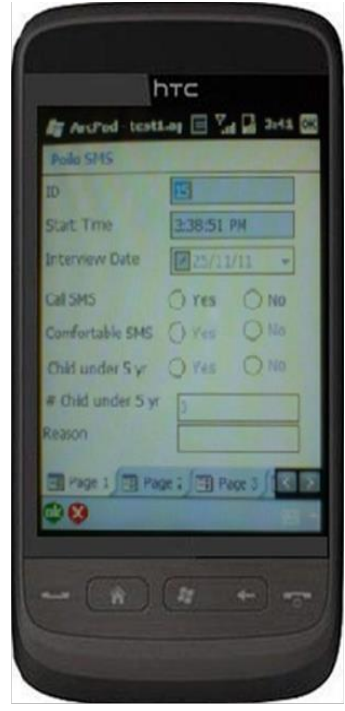

Smartphone and form for capturing data

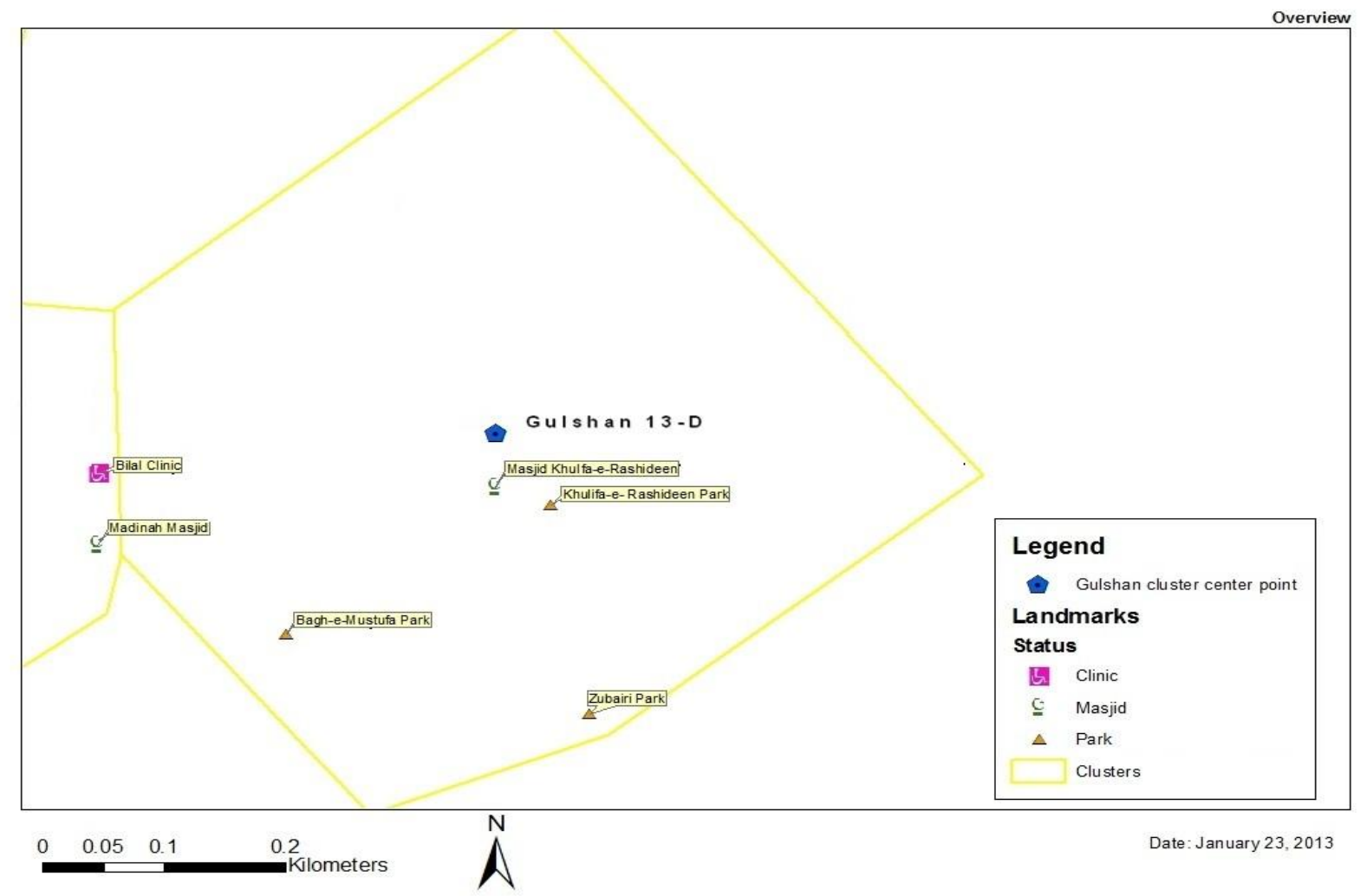

Figure 2: Methodology of the work flow at the community level. Cluster maps were incorporated in the smartphones with landmarks for direction and identification of field study staff 

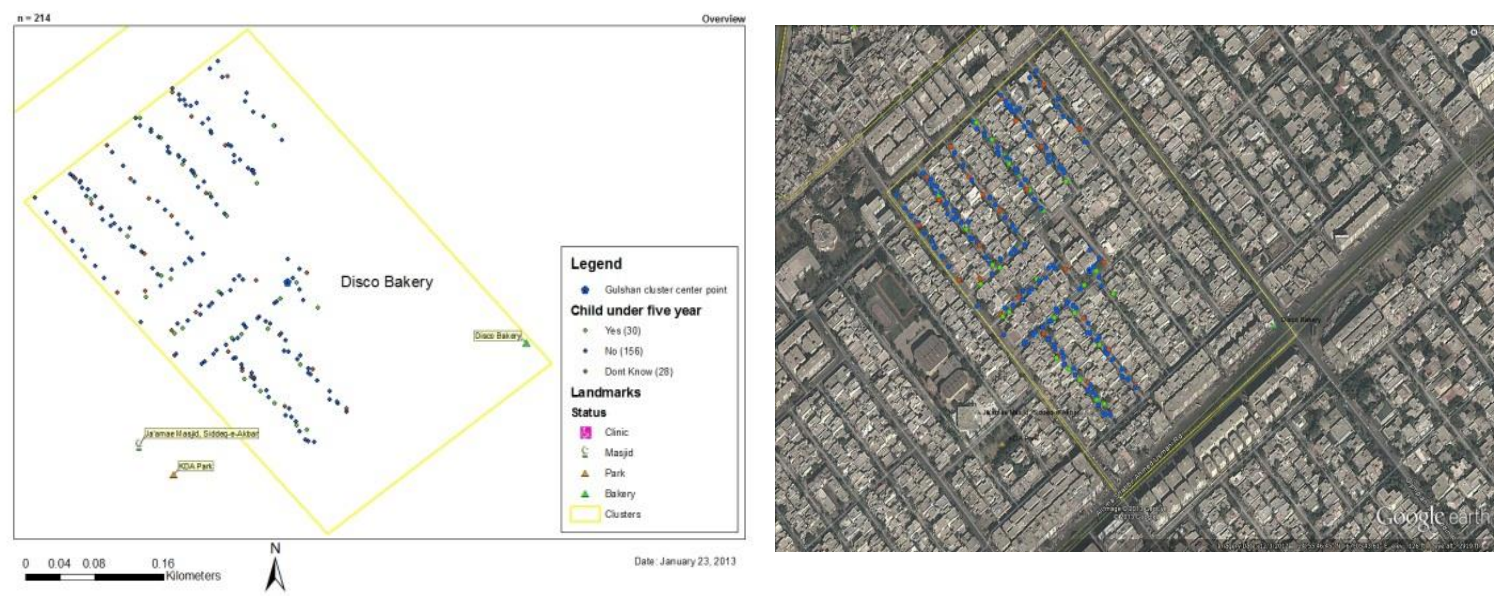

Figure 3: Daily activity maps were generated both on ArcGIS and Google Earth in order to visualize and collate the data. This helped in monitoring and looking into different aspects of the study 


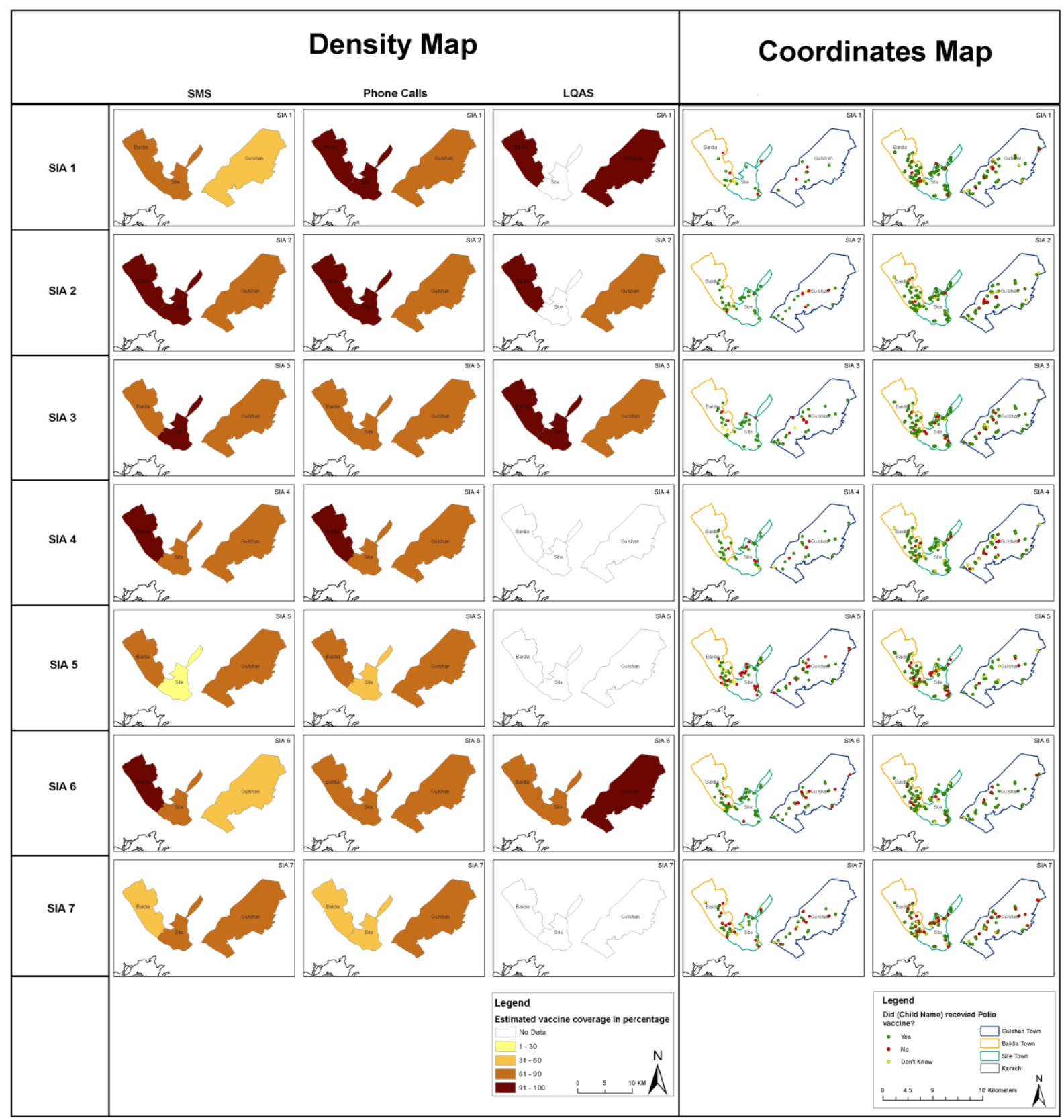

Figure 4:Denotesgeoreferencing of the replies on the question whether the child received the polio vaccine. The figure represents households in the clusters with town boundaries which were included in the baseline survey and participated in the seven SIAs included in the automated SMS polio study

Table 1: Baseline Data of Cell Phone Numbers $n=3535$

\begin{tabular}{|lll|}
\hline Gender & Frequency & Percent \\
Male & 1892 & 54 \\
Female & 1643 & 46 \\
Phone Service Provider & & \\
Telenor & 1,069 & 30 \\
Mobilink & 874 & 25 \\
Ufone & 610 & 17 \\
Warid & 583 & 16
\end{tabular}




\begin{tabular}{|c|c|c|}
\hline Zong & 399 & 11 \\
\hline \multicolumn{3}{|l|}{ Language Preference } \\
\hline Urdu & 2954 & 84 \\
\hline English & 508 & 14 \\
\hline Sindhi & 42 & 1 \\
\hline Others & 31 & 1 \\
\hline \multicolumn{3}{|l|}{ Time Preferred For SMS } \\
\hline Anytime & 3223 & 91 \\
\hline Evening & 117 & 3 \\
\hline Night & 104 & 3 \\
\hline Others & 91 & 2 \\
\hline \multicolumn{3}{|c|}{ Relationship of the child whose contact number is provided } \\
\hline Father & 2,183 & 62 \\
\hline Mother & 694 & 20 \\
\hline Uncle & 372 & 11 \\
\hline Grandparent & 146 & 4 \\
\hline Others & 140 & 4 \\
\hline \multicolumn{3}{|l|}{ Cell Company } \\
\hline Nokia & 2435 & 69 \\
\hline Samsung & 181 & 5 \\
\hline $\mathrm{LG}$ & 150 & 4 \\
\hline Other & 769 & 22 \\
\hline Having an alternative number & 1232 & 34.85 \\
\hline
\end{tabular}

Table2: Vaccine coverage's estimated by three methods, in three towns of Karachi, Pakistan, 2012-2013

\begin{tabular}{|c|c|c|c|c|}
\hline \multirow[t]{2}{*}{ Study areas and date of SIA } & \multirow[t]{2}{*}{ Sample } & \multicolumn{3}{|c|}{ Estimated vaccine coverage, $\%(95 \% \mathrm{CI})$} \\
\hline & & SMS & LQAS & $\mathbf{P C}$ \\
\hline \multicolumn{5}{|l|}{ SITE } \\
\hline March 2012 & $9 /-/ 135$ & $78(51-100)$ & ND & 93 (89-97) \\
\hline April 2012 & $21 /-/ 81$ & $95(86-100)$ & ND & $93(87-99)$ \\
\hline June 2012 & $22 / 150 / 96$ & $91(79-100)$ & $92(88-96)$ & $83(75-91)$ \\
\hline July 2012 & $24 /-/ 87$ & $83(68-98)$ & ND & $90(84-96)$ \\
\hline September 2012 & $77 /-/ 61$ & $29(15-43)$ & ND & $56(44-68)$ \\
\hline October 2012 & $37 / 50 / 68$ & $86(75-97)$ & $82(71-93)$ & $82(73-91)$ \\
\hline April 2013 & $20 /-/ 75$ & $65(44-85)$ & ND & $56(45-67)$ \\
\hline \multicolumn{5}{|l|}{ Baldia } \\
\hline March 2012 & $8 / 150 / 138$ & $63(30-96)$ & 93 (89-97) & 93 (89-97) \\
\hline April 2012 & $14 / 200 / 77$ & $93(80-100)$ & $92(88-96)$ & $96(92-100)$ \\
\hline June 2012 & $14 / 150 / 85$ & $86(68-100)$ & $94(92-98)$ & 87 (80-94) \\
\hline July 2012 & $18 /-/ 69$ & $94(83-100)$ & ND & $91(84-98)$ \\
\hline September 2012 & $33 /-/ 66$ & $73(58-88)$ & ND & $82(73-91)$ \\
\hline October 2012 & $31 / 50 / 75$ & $97(91-100)$ & 88 (79-97) & $88(81-95)$ \\
\hline April 2013 & $29 /-/ 73$ & $52(34-70)$ & ND & $56(45-68)$ \\
\hline
\end{tabular}




\begin{tabular}{|lllll|}
\hline Study areas and date of SIA & Sample & Estimated vaccine coverage, \% (95\% CI) \\
& & & LQAS & PC \\
\hline Gulshan-e-Iqbal & & & & \\
March 2012 & $15 / 100 / 108$ & $60(51-69)$ & $91(85-97)$ & $80(72-88)$ \\
April 2012 & $22 / 200 / 92$ & $68(49-87)$ & $89(84-93)$ & $83(75-91)$ \\
June 2012 & $38 / 150 / 77$ & $82(70-94)$ & $89(84-93)$ & $81(72-90)$ \\
July 2012 & $32 /-/ 82$ & $78(64-92)$ & ND & $82(74-90)$ \\
September 2012 & $46 /-151$ & $61(48-74)$ & ND & $76(64-88)$ \\
October 2012 & $57 / 50 / 68$ & $60(47-73)$ & $92(84-100)$ & $84(75-93)$ \\
April 2013 & $32 /-/ 73$ & $72(56-88)$ & ND & $66(55-77)$ \\
\hline
\end{tabular}

CI, confidence interval; LQAS, lot quality assurance sampling; ND, not determined; PC, phone calls; SIA, supplementary immunization activity; SMS, short message service. 